Supporting Information for

\title{
Local Structural Fingerprints of Nanoparticle-Bound Polymer
}

\section{Layers}

\author{
Ali Gooneie* \\ Laboratory of Advanced Fibers, Empa, Swiss Federal Laboratories for Materials Science and \\ Technology, Lerchenfeldstrasse 5, CH-9014 St. Gallen, Switzerland \\ *Corresponding Authors: ali.gooneie@empa.ch
}



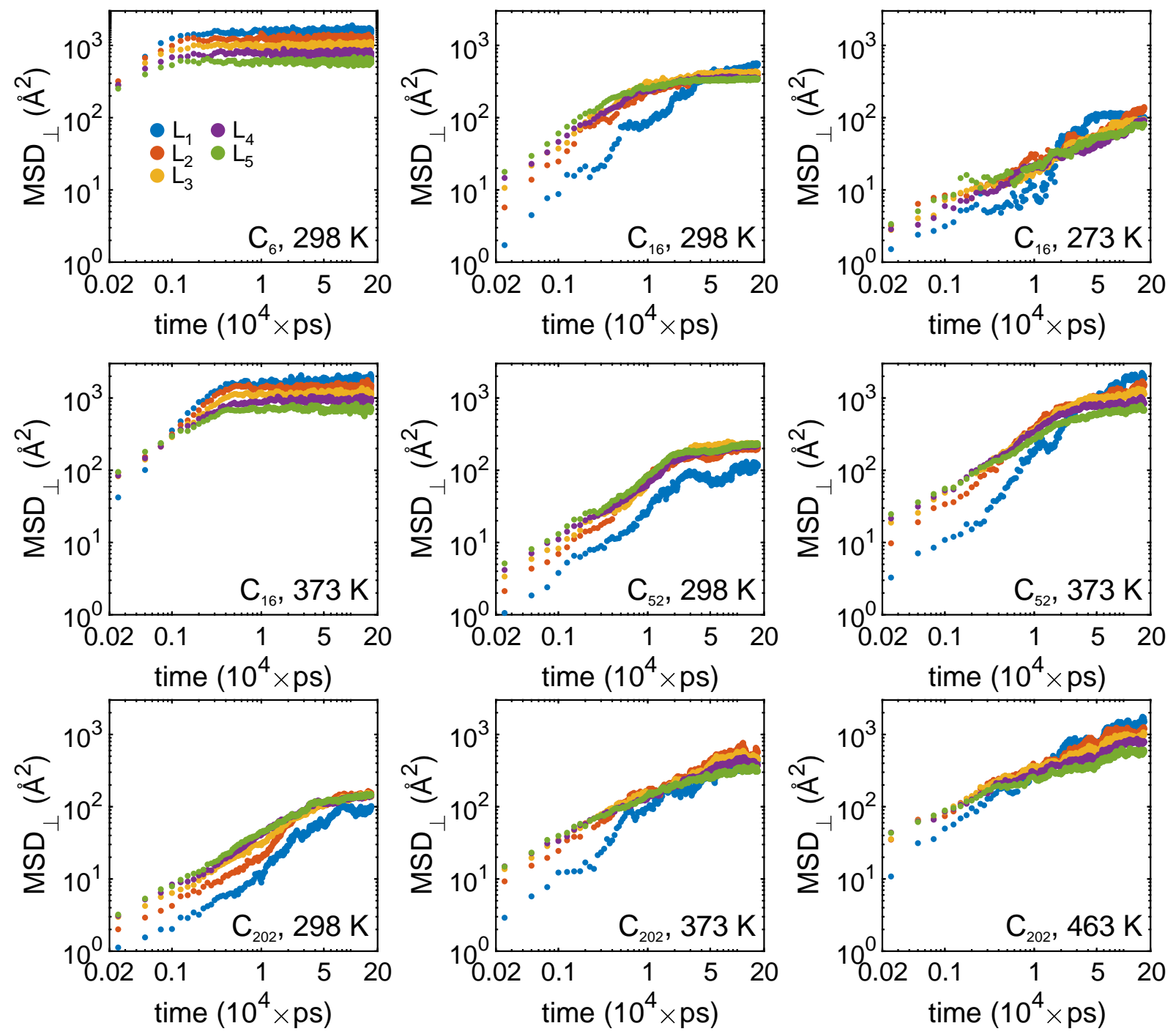

Figure S1. Mean squared displacements $(\mathrm{MSD} \perp)$ of polymer segments of different bound layers (legends shown in the first part of the figure) perpendicular to the CNT surface in simulated nanocomposites. 

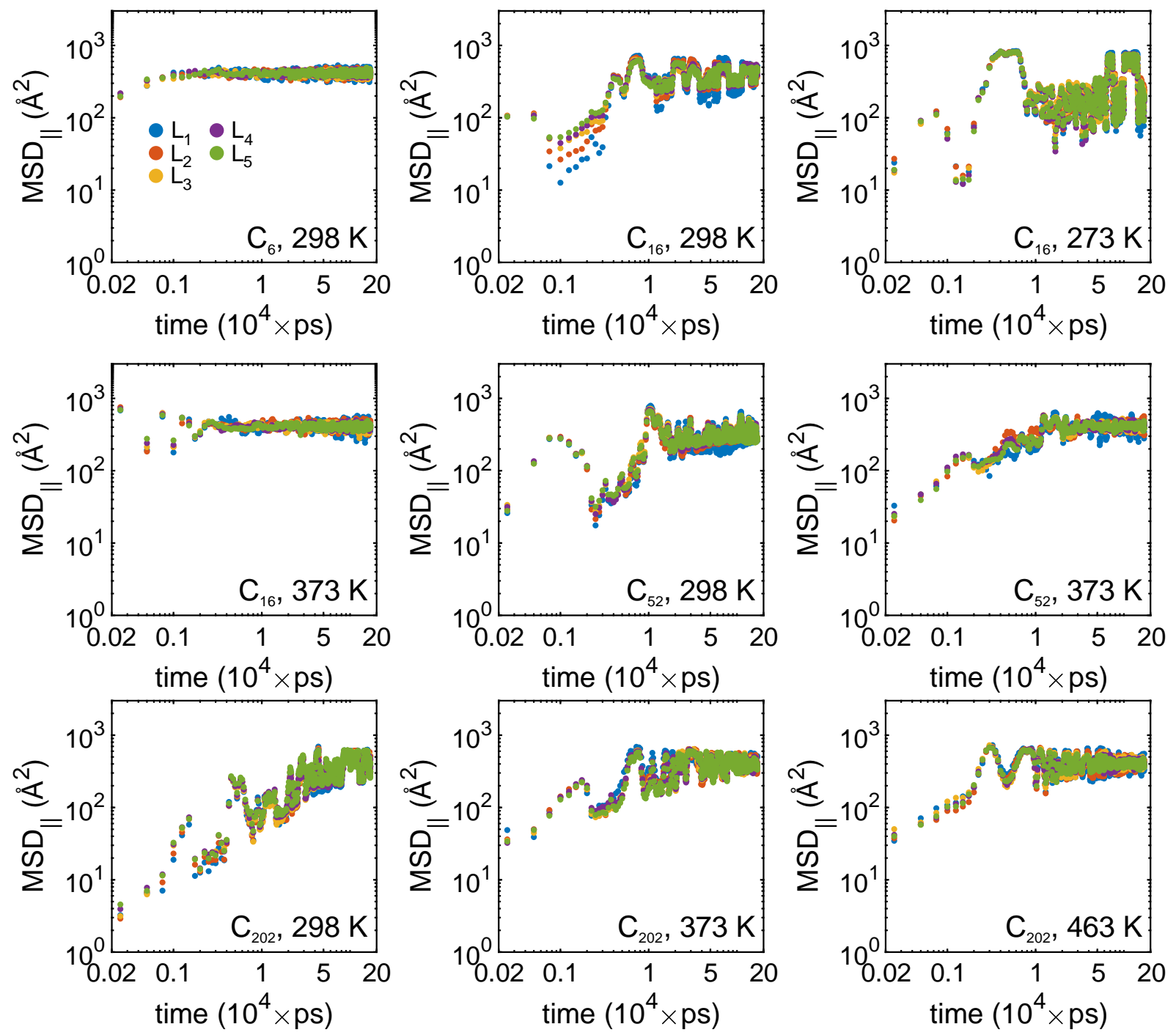

Figure $\mathrm{S} 2$. Mean squared displacements $\left(\mathrm{MSD}_{\|}\right)$of polymer segments of different bound layers (legends shown in the first part of the figure) parallel to the CNT surface in simulated nanocomposites. 